\title{
Exploration of Practice Path of General Education of Intangible Cultural Heritage in Higher Vocational Colleges
}

\author{
Lu Sun \\ Chongqing University of Posts and Telecommunications \\ Chongqing Vocational College of Culture and Arts \\ Chongqing, China
}

\begin{abstract}
Higher vocational colleges should vigorously develop the general education of intangible cultural heritage on the basis of respecting the law of protection of intangible cultural heritage to cultivate new cultural talents with the awareness of intangible cultural heritage protection, accurately locate teaching objectives and reasonably set teaching modules; Pragmatically design the teaching path, pay attention to the integration of general education of intangible cultural heritage and professional education content, and cultivate new cultural talents in the new situation through traditional classroom teaching, practical project operation, practical service activities, inheritance sharing salon and other practical education methods.
\end{abstract}

Keywords - higher vocational education; intangible cultural heritage; general education; practice path

\section{INTRODUCTION}

Nowadays, the protection of cultural ecosystem is increasingly valued. As the backbone of vocational education, higher vocational colleges play an increasingly important role in the protection, inheritance and popularization of intangible cultural heritage (hereinafter referred to as intangible cultural heritage).

\section{THE NECESSITY OF CARRYING OUT THE GENERAL EdUCATION OF INTANGIBLE CUlTuRAL HeRITAGE IN Higher VOCATIONAL COLLEGES}

The general education of intangible cultural heritage, which belongs to the category of general education, is universal education aiming at strengthening the awareness of the protection of intangible cultural heritage of students and improving the humanistic literacy and artistic literacy of students. The living environment of intangible cultural heritage in China is deteriorating rapidly. This kind of survival crisis is due in large part to people's shallow cognition of national cultural traditions, lack of protection awareness and inheritance concept. In some areas where the protection of intangible cultural heritage has been carried out, some of the difficulties faced by intangible cultural heritage deserve our attention: First, the development is conservative. The concept of some inheritors of intangible cultural heritage cannot keep up with the changes of the times, and the development and innovation are insufficient. Some intangible cultural heritage is considered to be not elegant due to lack of aesthetic feeling. Second, there are no inheritors. Due to the low economic efficiency and low social status of most non-legacy projects, people are reluctant to engage in project inheritance. Only a few old artists stick to some intangible cultural heritage, and there is no one to inherit their skills after they pass away. Third, the protection is single and superficial. Relying solely on the government's "blood transfusion" breeds the ideas of "waiting", "relying" and "wanting" of some intangible cultural heritage inheritors. The phenomenon of attaching importance to declaration and neglecting protection still exists objectively, and the publicity and promotion, video archiving and personnel training are not comprehensive and in-depth. Fourth, the development is secular and unintended. The protection and inheritance of some local intangible cultural heritage are limited to projects with economic value. After industrialization and commercialization, some intangible cultural heritage losses the due historical and cultural values ${ }^{1}$.

The existence of the above phenomenon is closely related to the lack of intangible cultural heritage protection talents in the region. To protect intangible cultural heritage, we must raise the awareness of Chinese people about traditional culture and raise the awareness of protection. As an important base for talent education and training, higher vocational colleges must assume the responsibility of protecting intangible cultural heritage. Without the popularization of general education, the whole society will not attach importance to intangible cultural heritage education, and there will be no population base to support the cultivation of professional education talents. The cultivation of intangible cultural heritage professionals can only be water without a source. Therefore, strengthening the cultivation of new cultural talents under general education is a measure to strengthen the source. 


\section{The Status QuO AND PROBLEMS OF GENERAL EDUCATION OF INTANGIBLE CULTURAL HERITAGE IN HigheR VOCATIONAL COLLEGES}

\section{A. The concept of general education of intangible cultural heritage has not been deeply accepted in higher vocational colleges}

At present, the concept of professional education of intangible cultural heritage has aroused the attention of the higher education circle to some extent, but the concept of general education of intangible cultural heritage, as a useful supplement to professional education, has not yet fully integrated. The concept of general education of intangible cultural heritage itself is rarely mentioned in the higher education system, attracting little attention, and not valued; The concept of general education and the concept of professional education are still in a state of contradiction and conflict, failing to achieve the full and beneficial integration of the two.

First of all, general education itself has not received due attention in some universities. Although some teachers and scholars have recognized the importance of general education and integrated general education into the higher education curriculum system, there are still many teachers who adhere to the traditional view in teaching practice and believe that general education courses are unimportant edge courses and formal courses, which are not conducive to professional education and also waste a lot of time, energy and educational resources, thus ignoring general education.

Second, most higher vocational colleges do not attach importance to general education of intangible cultural heritage. Higher vocational colleges attach great importance to the cultivation of students' applied skills. In some higher vocational colleges, relevant intangible cultural heritage professional skills training will also be paid attention to, but the general education of intangible cultural heritage is obviously not paid enough attention. Relevant higher vocational colleges will assign teaching tasks of general education of intangible cultural heritage to the general education department or the basic education department, and the department will assign tasks to various colleges (departments), but the colleges (departments) often aim at completing teaching tasks and eventually make the general education of intangible cultural heritage formalistic.

Third, there is still a competitive relationship between general education of intangible cultural heritage and relevant professional education. Although some higher vocational colleges offer courses, the general education of intangible cultural heritage is mutually exclusive with relevant professional education of intangible cultural heritage and other professional education, and there is a competitive relationship in terms of course setting and course quantity, failing to form an ideal integration relationship of mutual dependence, mutual supplement and mutual promotion.

\section{B. The setting of general education courses of intangible cultural heritage lacks applicability}

First of all, the content setting of intangible cultural heritage general education course is separated from the relevant professional courses. The setting of intangible cultural heritage general education course lacks clear teaching objectives and training direction, which makes the education administrators, teachers and students unable to effectively carry out the course. It is separated from the course setting of relevant majors, and fails to form an organic integration in terms of course content setting, cohesion and internal logic level, and the applicability of the course is poor.

Second, the content setting of intangible cultural heritage general education course is not perfect. Most of the higher vocational colleges that offer intangible cultural heritage general education courses often include the content related to the intangible cultural heritage major offered by the college into the teaching of intangible cultural heritage general education courses, highlight the advantages of the major and emphasizes the auxiliary and practical nature of intangible cultural heritage general education courses to relevant majors. However, they do not pay enough attention to the theoretical research system of the overall protection of intangible cultural heritage and ignore the humanistic and scientific nature of intangible cultural heritage general education courses, which is not conducive to improving the general scientific quality, humanistic quality and aesthetic level of students.

\section{The teaching form of the general education of intangible cultural heritage is relatively monotonous}

First of all, higher vocational colleges do not attach importance to the general education of intangible cultural heritage. Teachers and students tend to consider the importance of courses from the perspective of utility and practical effect. Even in colleges that offer general education of intangible cultural heritage, students tend to study professional courses seriously, but slack off in the study of intangible cultural heritage general education courses. Students' learning attitudes and teachers' teaching attitudes will influence each other in the course implementation. Under the premise that higher vocational colleges do not pay attention to general education of intangible cultural heritage, both teachers and students will have negative teaching and learning attitude, and the negative effect of the mutual influence will lead to the superficial and formal general education of intangible cultural heritage.

Secondly, the general education of intangible cultural heritage is often confined to books, which makes the teaching effect greatly reduced. On the one hand, although the classroom teaching of theoretical knowledge is indispensable, intangible cultural heritage has complex characteristics of cultural ecosystem, which means that it is very difficult for students to understand it through classroom teaching On the other hand, in terms of course evaluation, most higher vocational colleges offering intangible cultural heritage general education course often evaluate and score in a relatively loose form such as "checking" or open-book examination, and the requirements for such courses are inherently low, and the content of the course is either too shallow or not targeted, and 
it is difficult to achieve the goal of general education of intangible cultural heritage.

\section{Practice Path of General Education of INTANGIBLE CUltural HERITAGE IN Higher VoCATIONAL COLLEGES}

\section{A. Calibrate teaching objectives to meet the cultural heritage development needs}

The educational goal of intangible cultural heritage general education should be to cultivate new cultural talents with the awareness of intangible cultural heritage protection, the knowledge of intangible cultural heritage protection and the ability of intangible cultural heritage investigation; The purpose of the general education of intangible cultural heritage is to popularize relevant knowledge of intangible cultural heritage protection in a large range, improve the comprehensive quality of students and meet the needs of inheritance and development of traditional Chinese culture. This requires us to set the teaching objectives from the following three aspects.

\section{1) Consciousness and emotional objectives}

Students should have good cultural accomplishment, artistic accomplishment, aesthetic taste and etiquette knowledge facing the public and society, have sound personality, optimistic spirit and good temperament, consciously love Chinese traditional culture, and know how to respect the diversity of human culture in today's global context. Students need to emotionally recognize that intangible cultural heritage is an important manifestation of the diversity of human civilization and have the same status as the material wealth created by human beings.

\section{2) Knowledge and skill objectives}

Master the concept of intangible cultural heritage, understand the knowledge framework of "intangible cultural heritage", and grasp and use relevant skills to collect and explore traditional cultural resources to a certain extent; Be able to operate or work with a team to ensure the smooth progress of cultural and artistic activities; Understand the relevant laws and regulations of intangible cultural heritage protection, and be familiar with the etiquette norms that should be paid attention to in the relevant cultural industry.

\section{3) Ability and comprehensive quality objectives}

Have strong abilities to analyze and solve problems, express, communicate and cooperate with others; Have a love of traditional culture and social life, and have the consciousness of conscientiously fulfilling the duties of the post; Have the ability to work in a team, organize and coordinate work, and the ability of planning and operational skills.

\section{B. Reasonably set up teaching modules to cultivate new cultural talents}

Setting the corresponding teaching module content according to the established teaching objectives can not only be targeted to complete the teaching objectives, but also help the teaching staff to better grasp the nature of the course from the logic of teaching content, and integrate with the relevant professional teaching.

\section{1) Theoretical basis module}

Construct the basic theoretical knowledge framework with the basic concepts, types, characteristics, values and relevant laws and regulations of intangible cultural heritage as the teaching content The module aims to enable students to understand, familiarize and further master the basic theoretical knowledge of intangible cultural heritage, and gradually grasp the knowledge framework of "intangible cultural heritage", and finally achieve a certain professional level in theoretical knowledge and understanding of intangible cultural heritage, and also produce a strong and profound psychological resonance for the idea that the Chinese descendants must inherit and carry forward the traditional Chinese culture.

\section{2) Training skill module}

Taking the investigation and research of intangible cultural heritage, production protection and the construction and exploration of related cultural and ecological protection areas as the teaching content, guide students to conduct investigation and research of intangible cultural heritage to different degrees in this region (or in their major) by using relevant methods of field investigation and combining with their major. When conditions permit, further guide students to carry out enlightening exploration on the construction of local cultural ecological reserves.

\section{3) Practical literacy module}

With master workshops and intangible cultural heritage inheritor salons as carriers, group the students as required according to different types of intangible cultural heritage, develop students' ability of practical planning and teamwork under the mode of "workshop" and "teacher-apprentice system", and cultivate students' comprehensive quality of discovering and analyzing problems, communicating with others and finally solving problems in the process of teamwork.

\section{Practically design the teaching path to implement the teaching effect}

According to the relevant characteristics of general education of intangible cultural heritage, combined with the actual situation of each college, cautious and pragmatic, combined with new technology, new situation and new policies, rationally design the teaching paths to achieve the desired teaching effect.

1) Traditional classroom teaching, integrating and connecting relevant professional course contents

In terms of teaching content, the course content should be integrated and connected with the teaching content of intangible cultural heritage related majors, and the teaching content should be logical and hierarchical, so that students of different majors can feel the progressive knowledge system 
and the gradual increase of learning content in the whole learning process of the school, avoiding the fault or overlap of teaching content and improving the teaching efficiency.

2) Practical training project operation, relying on school-enterprise cooperation to establish a "workshop" project system

Establish master workshops, divide students into groups. Each group is led by teachers, related business personnel or directly by the inheritors, and the operation of different professional category projects is carried out according to the different majors of the students. Mainly by simulating professional operation process, or propaganda planning, or visiting and investigating, or experiencing inheritance, or even directly learning related intangible cultural heritage techniques, students of different majors can deepen their understanding and cognition of the ecological environment of intangible cultural heritage from the perspective of their respective majors.

3) Practice service activities, integrating the concept of "entrepreneurship and innovation" to create a cultural atmosphere

Higher vocational colleges can guide students to create a campus atmosphere on the basis of the concepts of "innovation" and "entrepreneurship" and the concept of ecological protection of intangible cultural heritage, with the "entrepreneurship and innovation" competition as a carrier, and integrating intangible cultural heritage cultural elements, and carry out propaganda and service activities according to the needs of the society and the people, which is a way for students to accumulate competition experience and social practice experience.

4) Inheritance sharing salon, establishing inheritor dialogue forums

Launch the "Inheritor Dialogue" activity on campus, and establish inheritor sharing salons and dialogue forums. Centering on the themes of traditional culture inheritance and promotion, such as "inheritance and creation" and "tradition around us", organize roundtable discussions based on the workshop to improve the design and production level and overall quality of traditional craft products according to different needs of students' majors, or design publicity planning program to increase public awareness in combination with the local intangible cultural heritage protection, or directly learn to inherit and serve enterprises and community cultural activities.

\section{CONCLUSION}

Higher vocational colleges should seize the historical opportunity, combine the talent training objectives, accurately locate the teaching objectives, reasonably set the teaching module, pragmatically design the teaching path, pay attention to the integration and connection of general education of intangible cultural heritage and professional education content, and cultivate new cultural talents adaptable to the situation and with good quality for the country and society through traditional classroom teaching, practical training project operation, practical service activities, inheritance sharing salons and other practical education methods.

\section{ACKNOWLEDGMENT}

Fund Project: humanities and social sciences research project of Chongqing Education Commission in 2016 "Research on Teaching Practice of General Education of Intangible Cultural Heritage in Higher Vocational Colleges" (16SKGH270); Higher Education Teaching Reform Research Project of Chongqing Education Commission in 2017 "Research on Innovation and Practice of Intangible Cultural Heritage General Education Course in Art Higher Vocational Colleges" (173290).

About The Author: Lu SUN (1987-), male, Han nationality, native of Yangzhou, Jiangsu, Chongqing University of Posts and Telecommunications, Chongqing College of Culture and Arts, associate professor, doctor.

\section{REFERENCES}

[1] Junhua SONG, Kaitao WANG. Research on the Protection of Intangible Cultural Heritage [M]. Guangdong: Sun Yat-Sen University Press, 2013: 106-115.

[2] Office of the Propaganda Department of the Central Committee of the CPC. Daily Essentials No. 1380 [Z]. 2018.

[3] Zhiqiang DU. Exploration of General Education in the Perspective of Higher Vocational Education [J]. Vocational and Technical Education, 2010 (6): $37-40$

[4] Hua SUN. The Ideal Type of General Education [J]. Education Research Monthly, 2015(4): 3-13

[5] Xiaoling YANG. Practical Exploration of the Integration of General Education and Professional Education in Application-oriented Colleges [J]. Education and Career, 2017(12): 101-104.

[6] Nengbiao WU, Huan LUO. Innovative Thinking and Practice of Talent Training Mode [J]. Chinese University Teaching, 2018(1): 51-55. 